\title{
TEM observation and fracture morphology in the CGHAZ of a new 0Cr18Mo2Ti ferritic stainless steel
}

\author{
LI YAJIANG*, ZHANG YONGLAN, SUN BIN and WANG JUAN \\ Key Laboratory of Liquid Structure and Heredity of Materials, Ministry of Education, School of Materials Science \\ and Engineering, Shandong University, Jinan 250061, P.R. China
}

MS received 7 June 2002; revised 12 August 2002

\begin{abstract}
Microstructure, precipitates and fracture morphology in the coarse grained heat-affected zone (CGHAZ) of a new high-purity 0Cr18Mo2Ti ferritic stainless steel were studied by means of optical metallography, SEM, TEM, X-ray diffractometer, etc. Experimental results indicated that grain coarsening resulted in brittle fracture in the CGHAZ of $0 \mathrm{Cr} 18 \mathrm{Mo2Ti}$ steel. The reduction of impact toughness in the CGHAZ due to change of cooling rate can be attributed to the increase of nitrides $\left(\mathrm{TiN}, \mathrm{Cr}_{2} \mathrm{~N}\right.$, etc). These nitrides in the CGHAZ promote initiation and propagation of brittle cracks. The precipitated $\mathrm{Cr}_{2} \mathrm{~N}$ nitrides in the grain boundaries decrease impact toughness in the CGHAZ of $0 \mathrm{Cr} 18 \mathrm{Mo2Ti}$ steel by promoting crack initiation. In practical applications, the welding heat input $(E)$ should be as low as possible to prevent toughness reduction in the CGHAZ.
\end{abstract}

Keywords. Ferritic stainless steel; electron microscopy; microstructure; fracture; heat-affected zone.

\section{Introduction}

With the development of vacuum melting technique (VMT), the interstitial elements $(\mathrm{C}, \mathrm{N}, \mathrm{O}$, etc) in ferritic stainless steels are reduced to lower levels. Trace elements are also added to steels, whereby, performance of the ferritic stainless steels improved remarkably (Krysiak 1986; Li et al 1995; Li and Zhang 1995), and the application of the ferritic steels also expanded. The welding of ferritic stainless steels also received more attention by researchers (Li and Zhang 1995; Nelson et al 1999; Dong et al 2000).

0Cr18Mo2Ti steel is a low carbon, low nitrogen highpurity ferritic stainless steel superior in pitting corrosion and crevice corrosion resistance, and especially to stress corrosion cracking resistance which is a serious problem in $18 \mathrm{Cr}-8 \mathrm{Ni}$ stainless steels. Ferritic stainless steels are generally considered to be susceptible to brittleness (loss of toughness and/or ductility) in the coarse grained heataffected zone (CGHAZ) after welding (Kah and Dickinson 1981). Impact toughness in the CGHAZ of the ferritic steels is so low that it leads to easy cracking in welded structures. Because of its low C, N and superior ductility, ferritic stainless steels are often used in solar energy collectors and for thin welded tubes in hot water environments.

To understand the welding characteristics of this new high-purity ferritic stainless steel, the microstructure, grain

\footnotetext{
*Author for correspondence
}

growth, precipitate and fracture morphology in the CGHAZ of 0Cr18Mo2Ti ferritic steels were studied. Some theoretical and experimental bases are provided for the welding of this high-purity ferritic stainless steel.

\section{Experimental}

The base metal used in the test was high-purity $0 \mathrm{Cr} 18$ Mo2Ti ferritic stainless steel produced by vacuum melting technique (VMT). The test materials were heated up to $850^{\circ} \mathrm{C}$, held for $10 \mathrm{~min}$ and then air-cooled. Thickness of the test plate was $3 \mathrm{~mm}$. The chemical composition and mechanical properties of $0 \mathrm{Cr} 18 \mathrm{Mo} 2 \mathrm{Ti}$ base metal are shown in table 1. $\mathrm{C}$ and $\mathrm{N}$ contents in the steel are reduced to about $190 \mathrm{ppm}$ and $140 \mathrm{ppm}$, respectively, to improve toughness using VMT process. The manufacturing process of $0 \mathrm{Cr} 18 \mathrm{Mo} 2 \mathrm{Ti}$ steel plate is shown in figure 1 .

Shielded metal arc welding (SMAW) with covered electrode was used in this study. The test electrode was the lime titania type super-low-carbon stainless steel electrode of $0 \mathrm{Cr} 18 \mathrm{Ni} 12 \mathrm{Mo} 2 \mathrm{Nb}$ system developed for use with $0 \mathrm{Cr} 18 \mathrm{Mo} 2 \mathrm{Ti}$ ferritic steel. Composition range of the deposited metal was (wt.\%): $\mathrm{C}<0.03, \mathrm{Cr} 17 \sim 20$, Ni $11 \sim 14$, Mo $1.5 \sim 2.5$. In addition, trace amounts of the Re element were added in the coating of the electrode to improve the impact toughness of the weld metal. Lower welding current and faster travel speed, viz. a low welding heat input $(E)$, were used in the test. Welding parameters used in the test are shown in table 2. 
Table 1. Chemical composition and mechanical properties of the base metal.

\begin{tabular}{|c|c|c|c|c|c|c|c|c|c|}
\hline \multicolumn{10}{|c|}{ Chemical composition (wt.\%) } \\
\hline $\mathrm{C}$ & $\mathrm{N}$ & $\mathrm{Mn}$ & $\mathrm{Si}$ & $\mathrm{Cr}$ & $\mathrm{Ni}$ & Mo & $\mathrm{Ti}$ & $\mathrm{S}$ & $\mathrm{P}$ \\
\hline $0 \cdot 019$ & $0 \cdot 014$ & $0 \cdot 28$ & $0 \cdot 16$ & $18 \cdot 65$ & $0 \cdot 14$ & $1 \cdot 60$ & $0 \cdot 24$ & $0 \cdot 005$ & $0 \cdot 024$ \\
\hline \multicolumn{10}{|c|}{ Mechanical properties } \\
\hline \multicolumn{3}{|c|}{ Tensile strength (MPa) } & \multicolumn{2}{|c|}{ Yield strength (MPa) } & \multicolumn{2}{|c|}{ Elongation (\%) } & \multicolumn{3}{|c|}{ Impact energy $(\mathrm{J})$} \\
\hline \multicolumn{3}{|c|}{$\begin{array}{c}550 \sim 700 \\
(560)^{*}\end{array}$} & \multicolumn{2}{|c|}{$\begin{array}{c}300 \sim 400 \\
(360)\end{array}$} & \multicolumn{2}{|c|}{$\begin{array}{c}30 \sim 40 \\
(34)\end{array}$} & \multicolumn{3}{|c|}{$\begin{array}{c}148 \sim 155 \\
(152)\end{array}$} \\
\hline
\end{tabular}

*Figures in parentheses are the test average value.

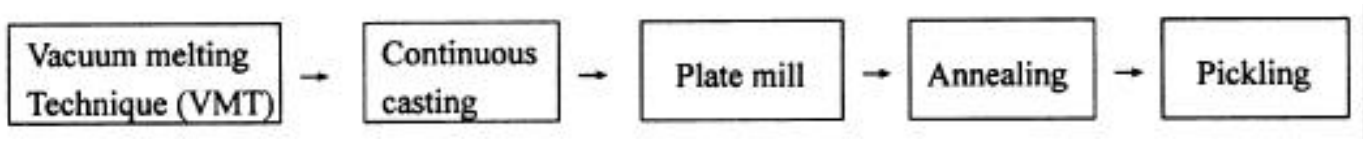

Figure 1. The manufacturing process of $0 \mathrm{Cr} 18 \mathrm{Mo} 2 \mathrm{Ti}$ ferritic steel.

Table 2. Welding parameters used in the test.

\begin{tabular}{lccc}
\hline $\begin{array}{l}\text { Diameter of } \\
\text { electrode } \\
(\mathrm{mm})\end{array}$ & $\begin{array}{l}\text { Welding } \\
\text { voltage } \\
\text { (volts) }\end{array}$ & $\begin{array}{l}\text { Welding } \\
\text { current } \\
(\mathrm{amps})\end{array}$ & $\begin{array}{c}\text { Welding travel } \\
\text { speed } \\
(\mathrm{mm} / \mathrm{s})\end{array}$ \\
\hline $3 \cdot 2$ & $24 \sim 26$ & $90 \sim 105$ & $6 \sim 8$ \\
\hline
\end{tabular}

The V-notch was prepared in the coarse grained heataffected region $(0.5 \mathrm{~mm}$ from the fusion line) of the 0Cr18Mo2Ti ferritic steel. Impact specimen size was $3 \times 10 \times 55 \mathrm{~mm}$. The fracture morphology and inclusions were analysed by means of a scanning electron microscope (SEM).

A series of samples were cut from the welded zone of the $0 \mathrm{Cr} 18 \mathrm{Mo} 2 \mathrm{Ti}$ ferritic stainless steel. A strong etchant (ratio of $\mathrm{HNO}_{3}$ and $\mathrm{HCl}$ was $1: 3$ ) was used to display microstructures of the weld zone. Microstructures and lattice structure in the coarse grained heat-affected zone of the 0Cr18Mo2Ti ferritic steel were analysed by means of optical microscopy, transmission electron microscopy (TEM) and electron diffraction. Phase constitution and precipitates in the CGHAZ were determined by X-ray diffraction, SEM and electron probe microanalysis (EPMA).

\section{Results and discussion}

\subsection{Impact toughness and microstructure}

Impact results and microstructure of $0 \mathrm{Cr} 18 \mathrm{Mo} 2 \mathrm{Ti}$ ferritic steel under different heat treatments are shown in table 3. When using the special electrode of $0 \mathrm{Cr} 18 \mathrm{Ni} 12 \mathrm{Mo} 2 \mathrm{Nb}$ system, microstructures in the weld metal of the
0Cr18Mo2Ti steel are austenite, ferrite and a little martensite. Microstructure morphology of the weld metal observed by SEM is shown in figure 2. During the fast cooling of the weld metal, the basic microstructure in the weld metal was austenite.

The ferritic stainless steel generally has lower toughness, especially in the coarse grained heat-affected zone of welded joint due to grain coarsening. The degradation of toughness in the coarse grained heat-affected zone is a serious problem since the CGHAZ is heated to 1200 $\sim 1350^{\circ} \mathrm{C}$. Results of $\mathrm{V}$-notch impact test for the welded zone of $0 \mathrm{Cr} 18 \mathrm{Mo} 2 \mathrm{Ti}$ ferritic steel are shown in figure 3 .

The microstructure of $0 \mathrm{Cr} 18 \mathrm{Mo} 2 \mathrm{Ti}$ steel is a singlephase ferrite. After heating and cooling during welding, the microstructure in the heat-affected zone did not undergo phase transformation (see figure 2B). But, the grain in the HAZ near the weld metal is obviously coarse compared with that of the base metal. The ferritic grain size in the HAZ is reduced with the increase in distance from the fusion zone. Because the HAZ near the weld metal is affected by the welding heat input, grain growth in this zone is obvious. Therefore, for welding of 0Cr18Mo2Ti ferritic steel, the welding heat input $(E)$ should be as small as possible during welding to prevent the overheated microstructure in the HAZ and the toughness reduction caused by grain coarsening. A lower welding current and faster travel speed can produce satisfactory results.

Samples of the welding zone of 0Cr18Mo2Ti steel were analysed by means of an X-ray diffractometer, using a copper target. The test conditions being the working voltage was $40 \mathrm{kV}$, the working current was $150 \mathrm{~mA}$ and the scanning range was $30 \sim 90$ degrees. The experi- 

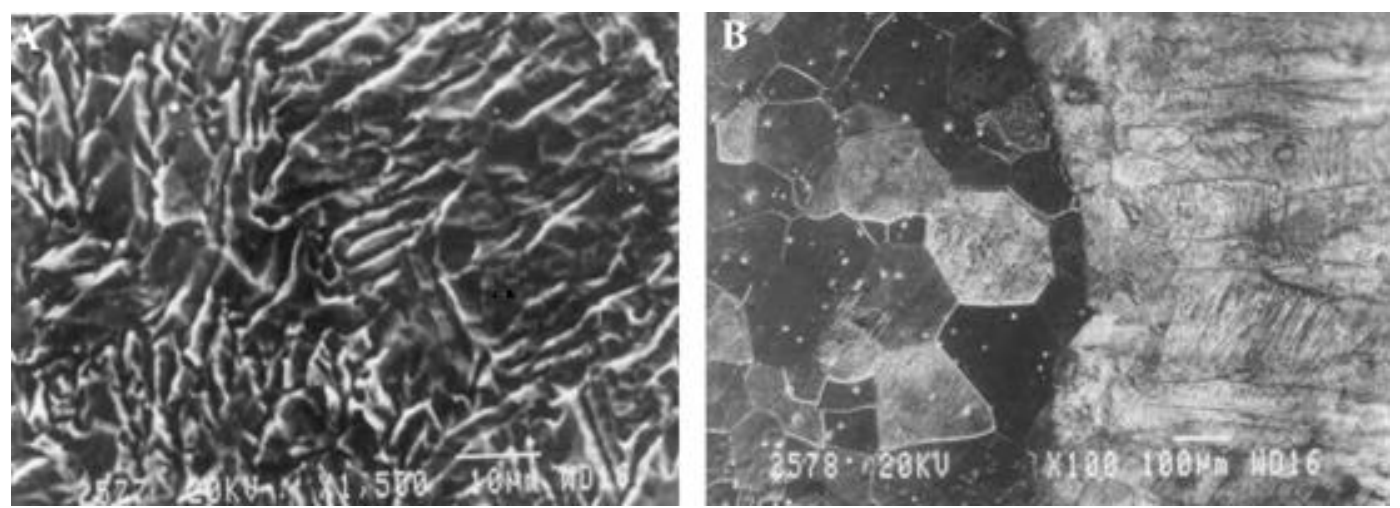

Figure 2. Microstructure of the weld metal and the HAZ of $0 \mathrm{Cr} 18 \mathrm{Mo} 2 \mathrm{Ti}$ ferritic steel (SEM): A. Weld metal $(\times 1500)$ and $\mathbf{B}$. weld metal and heat-affected zone $(\times 100)$.

Table 3. Impact energy and microstructure of $0 \mathrm{Cr} 18 \mathrm{Mo} 2 \mathrm{Ti}$ ferritic steel.

\begin{tabular}{lccc}
\hline & \multicolumn{3}{c}{ Condition of the heat treatment } \\
\cline { 2 - 4 } & $\begin{array}{c}1200^{\circ} \mathrm{C} \text { for } \\
\text { Test content }\end{array}$ & $\begin{array}{c}1200^{\circ} \mathrm{C} \text { for } \\
10 \mathrm{~min} \mathrm{~W} . \mathrm{Q} .\end{array}$ & $\begin{array}{c}10 \mathrm{~min} \text { A.C. } \\
1000^{\circ} \mathrm{C} \text { for }\end{array}$ \\
\hline $\begin{array}{l}\text { Impact energy F.C. } \\
\mathrm{J}\left(25^{\circ} \mathrm{C}\right)\end{array}$ & $\begin{array}{c}94,100,109 \\
(101)\end{array}$ & $\begin{array}{c}108,113,115 \\
(112)\end{array}$ & $\begin{array}{c}57,71,76 \\
(68)\end{array}$ \\
Microstructure & Ferrite $+\mathrm{Cr}_{2} \mathrm{~N}$ & Ferrite $+\mathrm{Cr}_{2} \mathrm{~N}$ & Ferrite $+\mathrm{Cr}_{2} \mathrm{~N}$ \\
\hline
\end{tabular}

Note: W.Q., water quenched, A.C., air-cooled, F.C., furnace cooled.

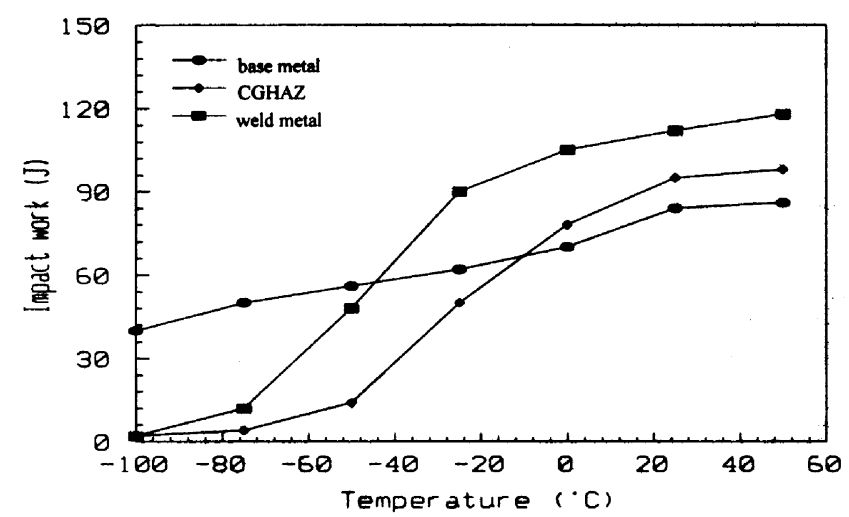

Figure 3. Results of V-notch impact test for the welded zone of $0 \mathrm{Cr} 18 \mathrm{Mo} 2 \mathrm{Ti}$ steel.

mental results indicated that the welding zone of $0 \mathrm{Cr} 18$ Mo2Ti steel consisted mainly of ferrite and austenite.

With the development of vacuum melting technique, it is possible to reduce the $\mathrm{C}$ and $\mathrm{N}$ contents of $18 \% \mathrm{Cr}$ steels to lower levels, $190 \mathrm{ppm}$ and $140 \mathrm{ppm}$, respectively. Therefore, the toughness of $0 \mathrm{Cr} 18 \mathrm{Mo} 2 \mathrm{Ti}$ steel with extremely low levels of $\mathrm{C}$ and $\mathrm{N}$ was improved. The reduction of $\mathrm{C}$ and $\mathrm{N}$ contents is effective in improving toughness and ductility of high $\mathrm{Cr}$ ferritic steel. However, reduction of $\mathrm{C}$ and $\mathrm{N}$ contents is not sufficient in all ferritic steel for structural use, consequently, 0Cr18Mo2Ti steel has been used only as thin plates and the welding heat input must be minimized.

\subsection{TEM observation}

To clarify further the fine microstructure morphology in the CGHAZ of 0Cr18Mo2Ti ferritic steel, thin foils from the CGHAZ and the fusion zone were analysed by TEM and electron diffraction. TEM morphology, electron diffraction pattern and index schematic diagram of the CGHAZ and the fusion zone of $0 \mathrm{Cr} 18 \mathrm{Mo} 2 \mathrm{Ti}$ ferritic steel, taken from [210] and [012] directions, are shown in figures $4 \mathrm{~A}-\mathrm{C}$ and $5 \mathrm{~A}-\mathrm{C}$, respectively.

TEM photographs (figures $4 \mathrm{~A}$ and $5 \mathrm{~A}$ ) of the CGHAZ and the fusion zone, sub-structure inside grain and distinct sub-grain boundaries may be seen. There are a large number of dislocations inside the grain. A number of dislocation lines and twin clusters, distributed from boundary to the interior of the grain, may also be observed. These dislocation lines and twins are probably the result of local deformation caused by the residual stress.

Electron diffraction for thin foil samples indicates that the diffraction pattern in the CGHAZ of $0 \mathrm{Cr} 18 \mathrm{Mo} 2 \mathrm{Ti}$ steel is $b c c$ ferrite $(\alpha-\mathrm{Fe})$, and the lattice constant is $0 \cdot 2866 \mathrm{~nm}$. The diffraction pattern (figure $5 \mathrm{~B}$ ) in the thin foil sample of the fusion zone is also ferrite $(\alpha-\mathrm{Fe})$. The TEM examination further confirmed that the crystal structure in the CGHAZ of $0 \mathrm{Cr} 18 \mathrm{Mo} 2 \mathrm{Ti}$ steel did not undergo significant phase transformation even after experiencing welding thermal cycle, except for the growth of the ferritic grain.

\subsection{Analysis of fracture and precipitates}

The fracture morphology in the CGHAZ of 0Cr18Mo2Ti steel was observed by means of SEM. The fracture mor- 
phology of CGHAZ near the fusion zone basically presented characteristics of a quasi-cleavage fracture (QC), except for a small amount of dimple at the place of fracture on the specimen edge. But, the size of the grain in the CGHAZ is coarse (see figures 6A, B). With larger welding heat input $(E)$, more of cleavage fracture was seen.

The fracture surface in the CGHAZ of 0Cr18Mo2Ti steel has the typical characteristics of the river pattern (see figure 6C) and displays a cleavage tongue. The function of precipitates may be explained by Storch's theory of the dislocation pile-up (Yajiang Li et al 1996). According to the trend of the river pattern and from that of the cleavage tongue, the origin of the cleavage cracks can be judged. In most cases, the cleavage cracks originated from precipitates in the centre of the radiation-shaped pattern.
The precipitates at the grain boundary in the CGHAZ were examined by means of SEM and EPMA. Some precipitates presented regular geometrical shape. The precipitates were analysed by EPMA and it was found that Ti content was higher $(97.4 \% \mathrm{Ti})$. Typical precipitates and EPMA analysis spectra are shown in figures $7 \mathrm{~A}-\mathrm{C}$. The analysis indicated the precipitates to be $\mathrm{TiC}, \mathrm{TiN}$ or $\mathrm{Ti}(\mathrm{C}, \mathrm{N})$.

Further analysis indicated that precipitates ( $\mathrm{TiC}$, TiN and $\mathrm{Cr}_{2} \mathrm{~N}$, etc) distributed in the CGHAZ promote initialization and propagation of the cleavage crack. These precipitates strongly hinder the movement of dislocations during deformation, producing dislocation pileups and causing a stress concentration. This results in the formation of the cleavage cracks near precipitates and the propagation along the cleavage surface until fracture.
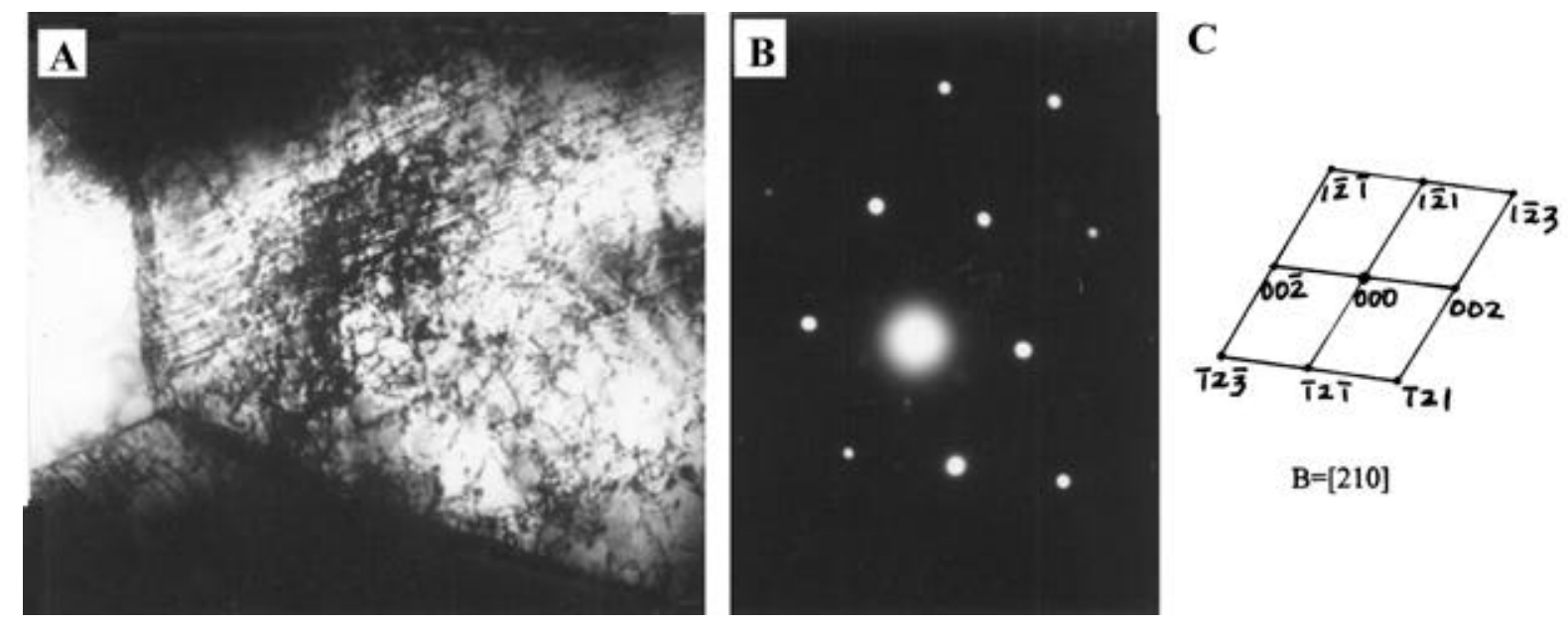

Figure 4. Structure characteristics in the CGHAZ of 0Cr18Mo2Ti ferritic steel: A. TEM morphology $(\times 35,000)$, B. electron diffraction pattern and C. schematic diagram.
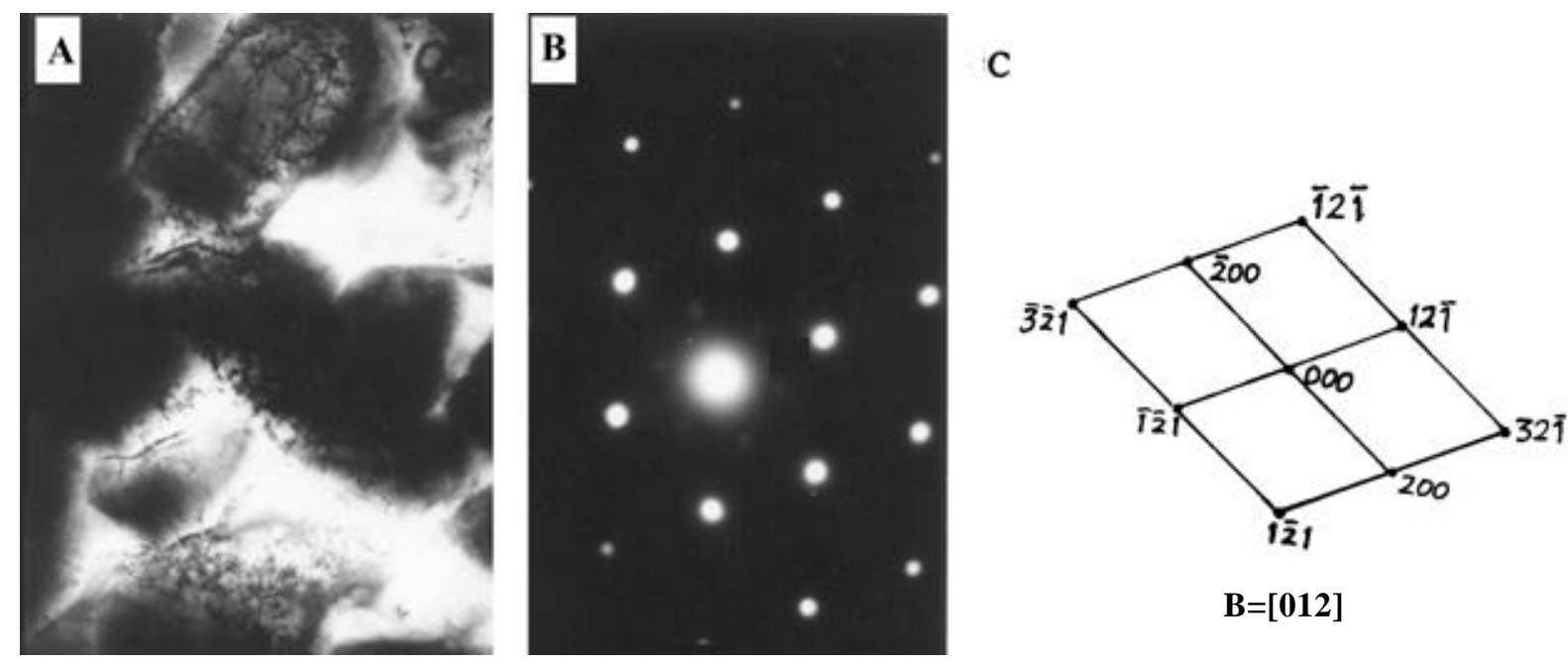

Figure 5. Structure characteristics in the fusion zone of $0 \mathrm{Cr} 18 \mathrm{Mo} 2 \mathrm{Ti}$ ferritic steel: A. TEM morphology $(\times 35,000)$, B. electron diffraction pattern and C. schematic diagram. 

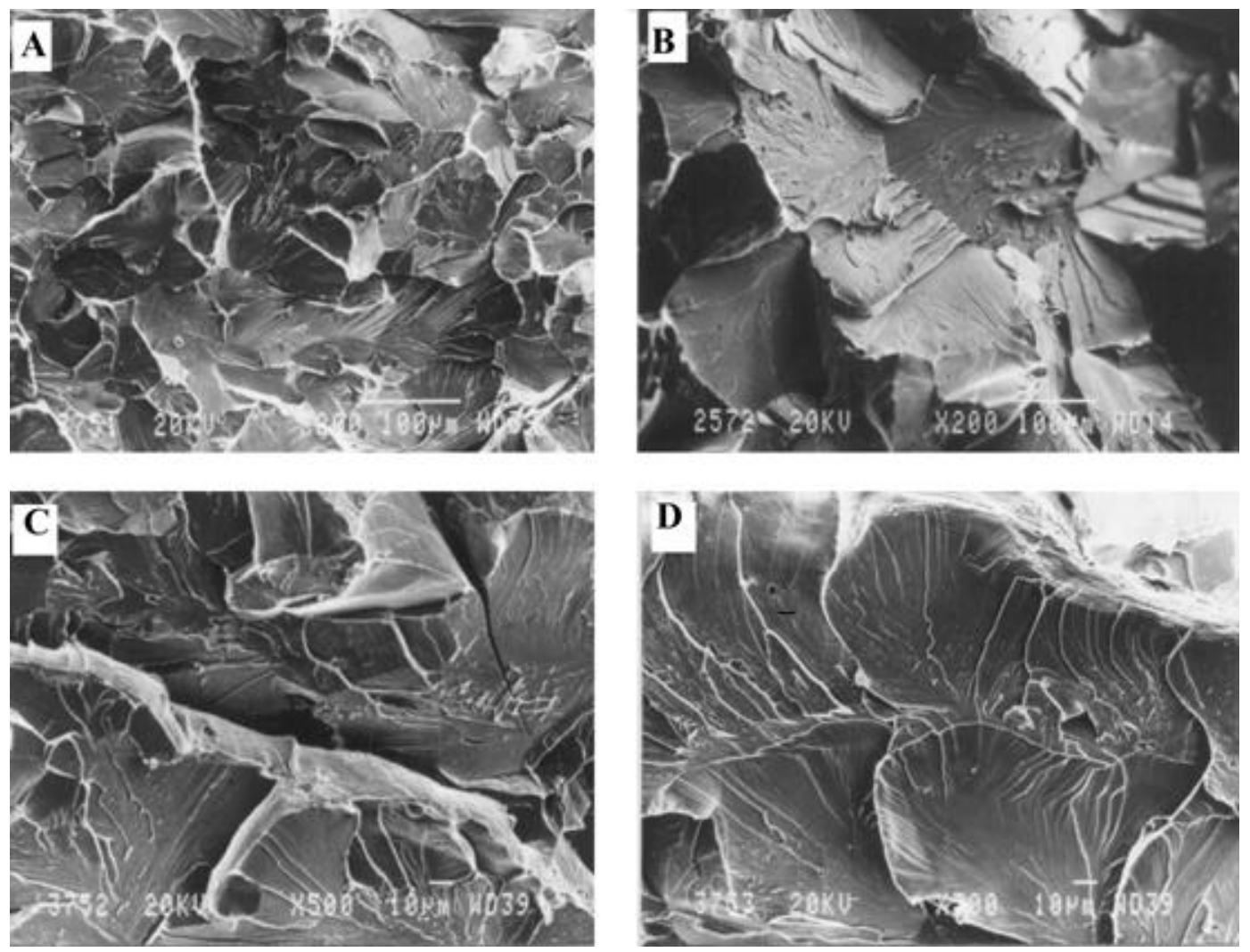

Figure 6. Fracture morphology in the CGHAZ of $0 \mathrm{Cr} 18 \mathrm{Mo} 2 \mathrm{Ti}$ ferritic steel (SEM): A. Base metal $(\times 200)$, B. coarse grained heat-affected zone $(\times 200)$, C. micro-crack $(\times 500)$ and D. river pattern in the CGHAZ $(\times 500)$.
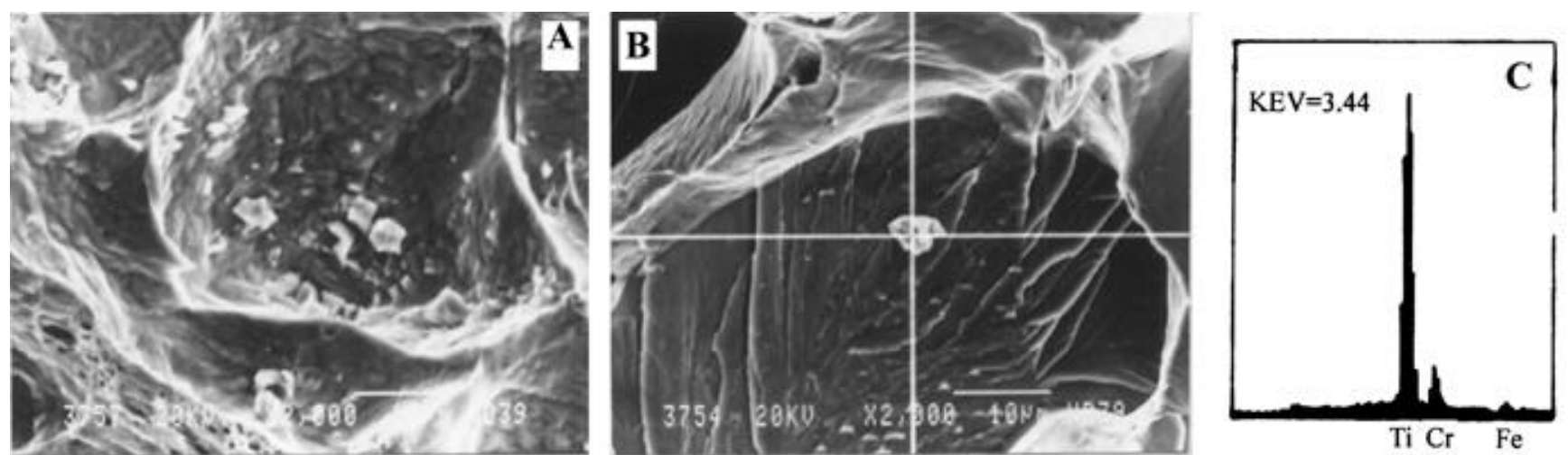

Figure 7. Precipitates in the CGHAZ of $0 \mathrm{Cr} 18 \mathrm{Mo} 2 \mathrm{Ti}$ ferritic steel (SEM and EPMA spectra): A. Precipitates in the CGHAZ $(\times 2000)$, B. analysis position of EPMA $(\times 2000)$ and C. EPMA spectra.

Impact energy in the CGHAZ decreases with decrease in cooling rate after welding. The change in toughness in the CGHAZ is also attributed to an increase in nitrides $\left(\mathrm{Cr}_{2} \mathrm{~N}, \mathrm{TiN}\right.$, etc). Carbide and nitride of $\mathrm{Cr}$ or of stabilizing elements precipitate at grain boundary in much greater amounts with lower cooling rate, and their presence renders the grain boundary more susceptible to cracking. In addition, the precipitated $\mathrm{Cr}_{2} \mathrm{~N}$ at the grain boundary decreases toughness in the CGHAZ of 0Cr18Mo2Ti steel by providing crack initiation and promote the propagation of the cleavage cracks.

When $\mathrm{C}, \mathrm{N}$ and $\mathrm{S}$ contents are high in the steel, $\{100\}$ surface is the separating surface of the second phase, and second phase here has an obvious tendency to precipitate. Feature of brittleness in the CGHAZ of 0Cr18Mo2Ti steel is due to a higher content of $\mathrm{C}, \mathrm{N}$ and $\mathrm{S}$ which 
facilitates formation of the interstitial phase along $\{100\}$ surface.

The fracture appeared as cleavage fracture along $\{100\}$ surface of ferrite. Some inclusions are precipitated on the $\{100\}$ cleavage surface. From the electron diffraction pattern of inclusions, these precipitates may be determined as $\mathrm{M}_{23} \mathrm{C}_{6}$ whose lattice constant is near to $1.064 \mathrm{~nm}$. In addition, there are also some bigger particles $\operatorname{Ti}(\mathrm{C}, \mathrm{N})$ whose size is about $2 \mu \mathrm{m}$ or so on the cleavage surface. These precipitates promote the initiation and propagation of the cleavage cracks. In the CGHAZ of $0 \mathrm{Cr} 18 \mathrm{Mo} 2 \mathrm{Ti}$ steel, precipitates $\left(\mathrm{TiC}, \mathrm{TiN}, \mathrm{Cr}_{2} \mathrm{~N}\right.$, etc) can effectively hinder the movement of dislocations and result in the formation of cleavage cracks. In most cases, the cleavage surface in the ferritic steel is produced on the $\{100\}$ surface and the cleavage cracks propagate along the $\langle 110\rangle$ direction on $\{100\}$ surface (Yajiang et al 1996).

There are some minute cracks around the precipitates containing $\mathrm{Ti}$ and $\mathrm{Cr}_{2} \mathrm{~N}$ on the cleavage surface. Whether these minute cracks formed before the cleavage cracks arrived or appeared during the propagation of the cleavage cracks is not clear. However, it shows clearly that precipitates promote the propagation of cracks on the cleavage surface.

\section{Conclusions}

(I) Microstructure in the CGHAZ of the 0Cr18Mo2Ti ferritic steel after welding thermal cycle does not show any phase transformation. But, there is precipitation of carbides and nitrides, and the ferritic grain in the CGHAZ has the trend of grain growth. Therefore, welding heat input $(E)$ should be as low as possible to prevent toughness reduction caused by grain coarsening.
(II) Impact fracture in the coarse grained heat-affected zone (CGHAZ) of $0 \mathrm{Cr} 18 \mathrm{Mo} 2 \mathrm{Ti}$ steel presented characteristics of cleavage fracture. The larger welding heat leads to greater cleavage fracture. The reduction in toughness in the CGHAZ and the change of fracture morphology is attributed to the increased nitrides $\left(\mathrm{Cr}_{2} \mathrm{~N}\right.$, TiN, etc) .

(III) There are some precipitates $\left(\mathrm{TiC}, \mathrm{TiN}\right.$ and $\mathrm{Cr}_{2} \mathrm{~N}$, etc) in the CGHAZ of 0Cr18Mo2Ti ferritic steel. The precipitated $\mathrm{Cr}_{2} \mathrm{~N}$ nitrides decrease toughness in the CGHAZ of ferritic steel by providing crack initiation and promote the propagation of the cleavage cracks along the $\langle 110\rangle$ direction on $\{100\}$ surface.

\section{Acknowledgements}

This work was supported by the Visiting Scholar Foundation of the National Key Laboratory of Advanced Welding Production Technology, Harbin Institute of Technology, P.R. China. The authors express their heartfelt thanks here.

\section{References}

Krysiak K F 1986 Welding J. 6537

Li Yuqing, Wang Cirong and Liu Xuesheng 1995 Iron and Steel 3045

Li Yajiang and Zhang Yonglan 1995 Trans. China Welding Inst. 16130

Dong Junhui, Yao Jun, Li Jianguo and Xia Xiangdong 2000 Trans. China Welding Inst. 2194

Nelson T W, Lippold J C and Mills M J 1999 Welding J. 78 $329 \mathrm{~s}$

Kah D H and Dickinson D W 1981 Welding J. 60 135s

Yajiang Li, Zengda Zou and Thompson M 1996 J. Mater. Sci. Technol. 12452 